\title{
Knowledge and Practice of Interdental Cleansing Aids among the Undergraduate and Post Graduate Students
}

\author{
Dr. Saleem Khan Postgraduate Student Department of Periodontology Midsr Latur \\ Dr. Om K Professor Department of Periodontology
}

Abstract:-

\section{$>$ Introduction:}

Bacterial plaque is the dominant etiological factor in periodontitis, furthermore it has been convincingly demonstrated that gingivitis is most frequent and most severe in interproximal area. Tooth brushing is indispensable for maintaining oral hygiene. However tooth brushing alone is not sufficient in interproximal area. Interdental aids provide auxiliary assistance. Lack of use of these may leads to interproximal caries and periodontitis.

\section{Aims and Objectives:}

This study is carried out to assess the knowledge and practice about interdental cleansing aids among undergraduate \& postgraduate students of MIDSR Dental College Latur.

\section{Methodology:}

A Cross-sectional Questionnaire Survey was carried out among Undergraduate and Post -Graduate Students of MIDSR Dental College Latur. They were divided into three groups[Group A -IST \& IInd years, Group B -IIIrd \& IV year, Group C consist of Interns and post-graduate students]. A prepared questionnaire is distributed to all subjects participating in the study and answers are collected in presence of principal investigator. Appropriate statistical analysis will be performed.

\section{$>$ Results:}

Among 465 subjects 324 voluntarily participated in the study. The knowledge and awareness was found to be 69.53\% in Group A, 96.33\% of Group B \& $100 \%$ among Group C. while $55.38 \%$ in group $A, \mathbf{6 2 . 3 8 \%}$ in group B and $66.67 \%$ in group $C$ are practicing interdental aids.

\section{Conclusion:}

The preliminary data shows that dental student is quite aware and knows about interdental cleansing aids, very less population practicing it. Practicing interdental cleansing aids will benefit for maintaining of oral hygiene, for plaque control, and for prevention of periodontal disease and Dissemination of information about the importance of interdental cleaning is therefore recommended.

\section{INTRODUCTION}

Dental plaque is the community of microorganisms found on a tooth surface as a biofilm, embedded in a matrix of polymers of host and bacterial origin. ${ }^{1,2}$ Dental plaque or biofilm is the main etiological factor in the causation of periodontal disease and effective removal of bacterial plaque is the gold standard for its prevention. The mechanical method of plaque control is indisputably the easiest and most effective measure to prevent periodontal diseases. ${ }^{3,4}$ It has been reported that toothbrush alone is inadequate for effective removal of dental plaque. ${ }^{5}$ Self-cleaning of the teeth provides mechanical removal of bacteria plaque, which if adequately carried out leaves the dental surfaces free. Incorporation of the appropriate skills of tooth cleaning should include all the teeth surfaces with emphasis on interdental areas that have been reported as the initiating sites for periodontal diseases. ${ }^{6}$ Similarly, the interdental surfaces are the most implicated locations for the development of periodontal diseases and dental caries. ${ }^{4}$ Gingival inflammation is, in addition, worst in these areas.

Although the toothbrush remain the most commonly used nonprofessional means of bacteria plaque control, it may leave the interdental areas incompletely cleaned of bacteria plaque thus additional conscious and regular cleaning with interdental cleaning aids is required. ${ }^{4,7}$

Common interdental cleaning aids include dental floss, interdental wood sticks, interdental brushes and tapes. The use of any of these aids is mostly dependent on the morphology of the interproximal tooth surface, the size and shape of the interdental area as well as patient factor in maintaining oral hygiene. ${ }^{7}$ Recent studies have shown that interdental cleaning of teeth with the appropriate aids reduces plaque accumulation and gingivitis, and that interdental cleaning is not associated with periodontal pocketing. ${ }^{7,8}$ However, most people tend to neglect this important habit, cleaning all other tooth surfaces and leaving the interdental areas untouched as the task is tedious, require meticulousness, as well as good manual skills. $^{9}$

\section{$>$ Aim and Objectives}

This study is carried out to assess the knowledge and practice about interdental cleansing aids among undergraduate $\&$ postgraduate students. 
Methodology

A Cross-sectional Questionnaire Survey was carried out among UG and PG Students of MIDSR Dental College Latur. A questionnaire of 18 multiple choice questions were given to
ISSN No:-2456-2165

dental student 324 subjects were grouped into Group A - ${ }^{\mathrm{ST}}$ \& II $^{\text {nd }}$ years students ,Group B -III ${ }^{\text {rd }} \&$ IV year students and Group C consist of Interns and postgraduate students.

\section{Questionnaire}

1) What do you use for cleaning the teeth?

Tooth Brush \& toothpaste only

Tooth Brush \&toothpaste+ interdental cleansing aids

Interdental cleansing aids only

None of these

2) Do you know about interdental cleansing aids?

$\square$ Yes

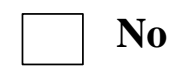

3) If yes, how come you know that?

Through mass media/advertising

$\square$ Through dentist

Family

$\square$ Other sources

4) Why it is used?

$\square$ To remove food accumulation

To remove stain

When there is a bleeding

Don't know exactly

5) In what kind or form it is available?

Cone -shaped /cylindrical brush

Wooden /rubber tips

Floss

All of the above 
6) Do you clean your teeth with interdental cleansing aids?

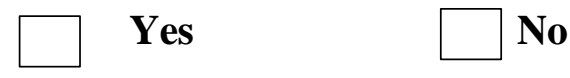

7) Do you regularly clean your teeth with interdental cleansing aids?
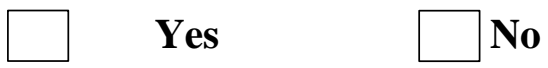

8) If yes, which type of interdental cleansing aids you used?

\section{Dental floss}

Tooth pick

Rubber tips

Interproximal brush

9) When did you start using interdental cleansing aids?

After advice of a dentist

Before joining dental college

After joining dental college

Any other

10) Is it time consuming?

$\square$ Yes

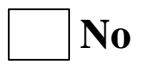

11) Is there any harmful effect on soft tissue during the use?

Yes No 
12) At what interval do u use?

Daily

Once in a week

Twice in a week

pnce in a month

13) How much time do you spend for cleaning the teeth with interdental cleansing aids?

- 2-3 MIN

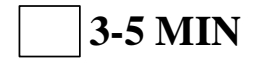

5-10 MIN

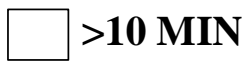

14) Are you happy with the use of interdental cleansing aids?

Yes

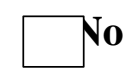

15) What secondary methods do you employ other than brushing for maintaining oral hygiene?

Mouthwashes

Ayurvedic / Herbal tooth powder

$\square$ Neem stick /Miswak stick

Any other

(For post graduates student and intern only)

16) Do you recommend your patients to use interdental cleansing aids?

$\square$ Yes

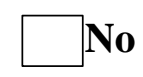

17) If yes How many times a day?

$\square$ Once a daily

Thrice
Twice

after every meals

18) At what time?

Before meals

After meals 


\section{RESULTS}

Among 465 subjects 324 voluntarily participated in the study. The knowledge and awareness was found to be $69.53 \%$ in Group A, $96.33 \%$ of Group B \& $100 \%$ among Group C. while $55.38 \%$ in group A, $62.38 \%$ in group B and $66.67 \%$ in group C are practicing interdental aids.

\section{KNOWLEDGE}

Do you know what are interdental aids?

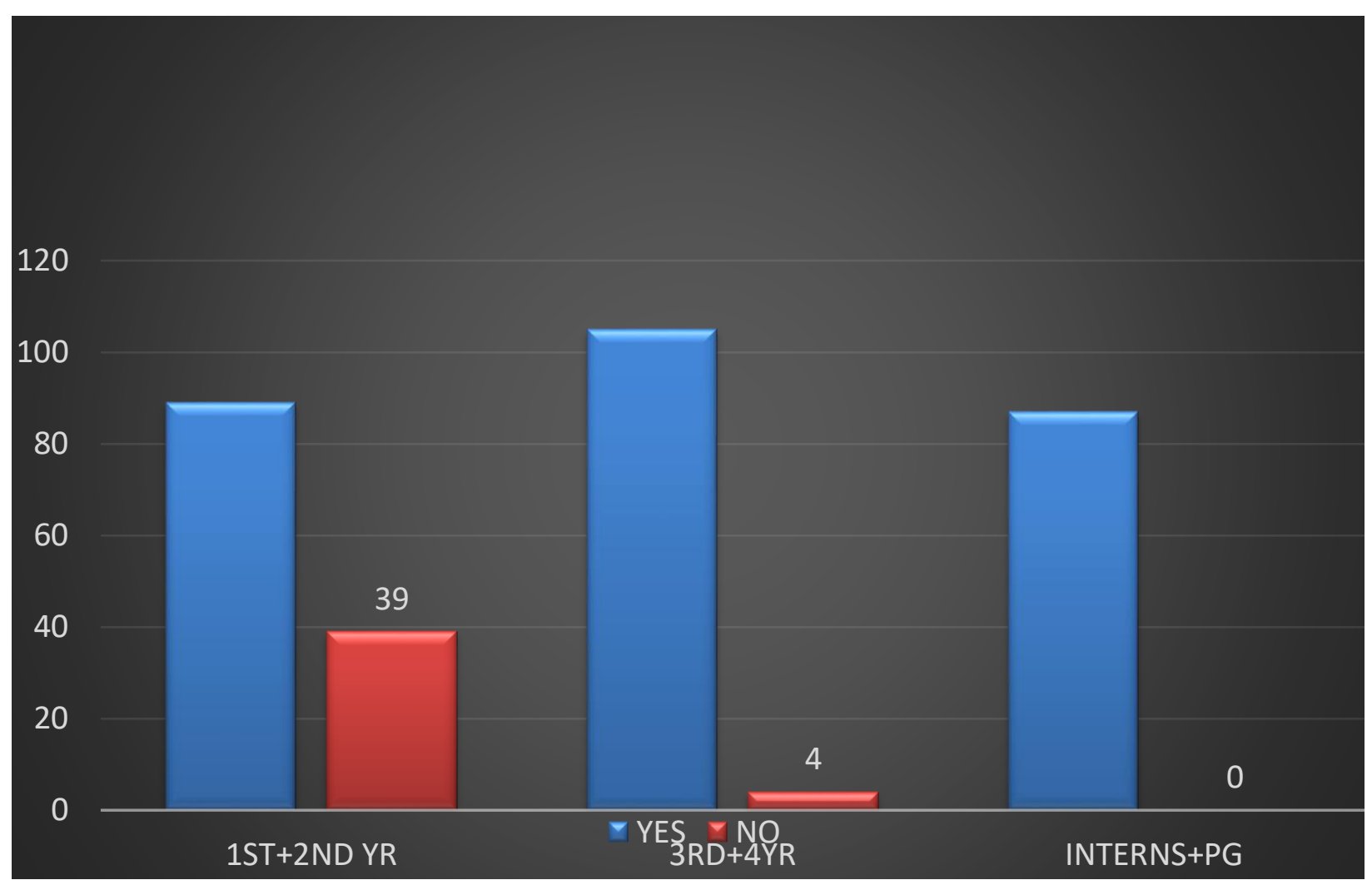

How come you know that? 


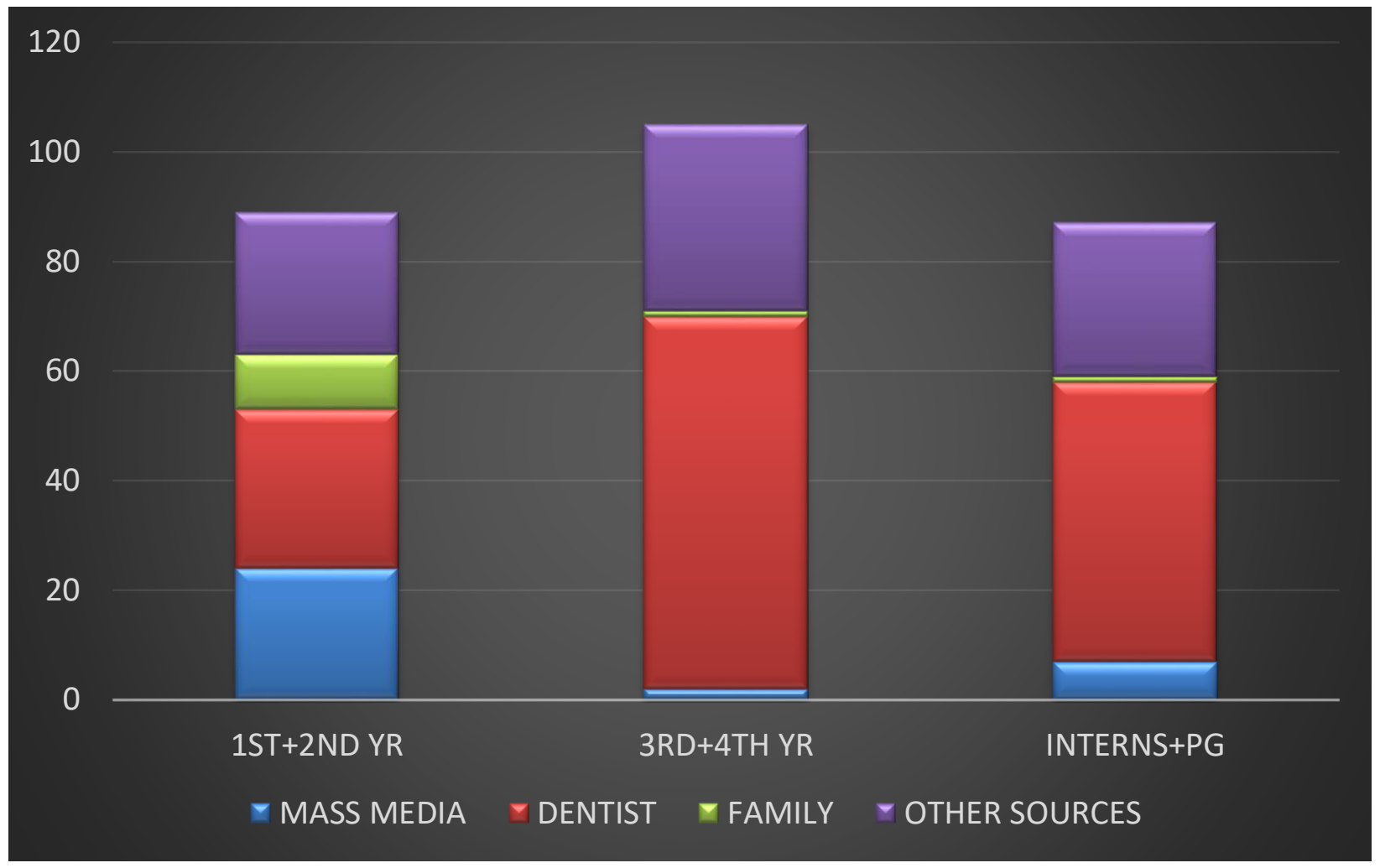

In what kind or form it is available?

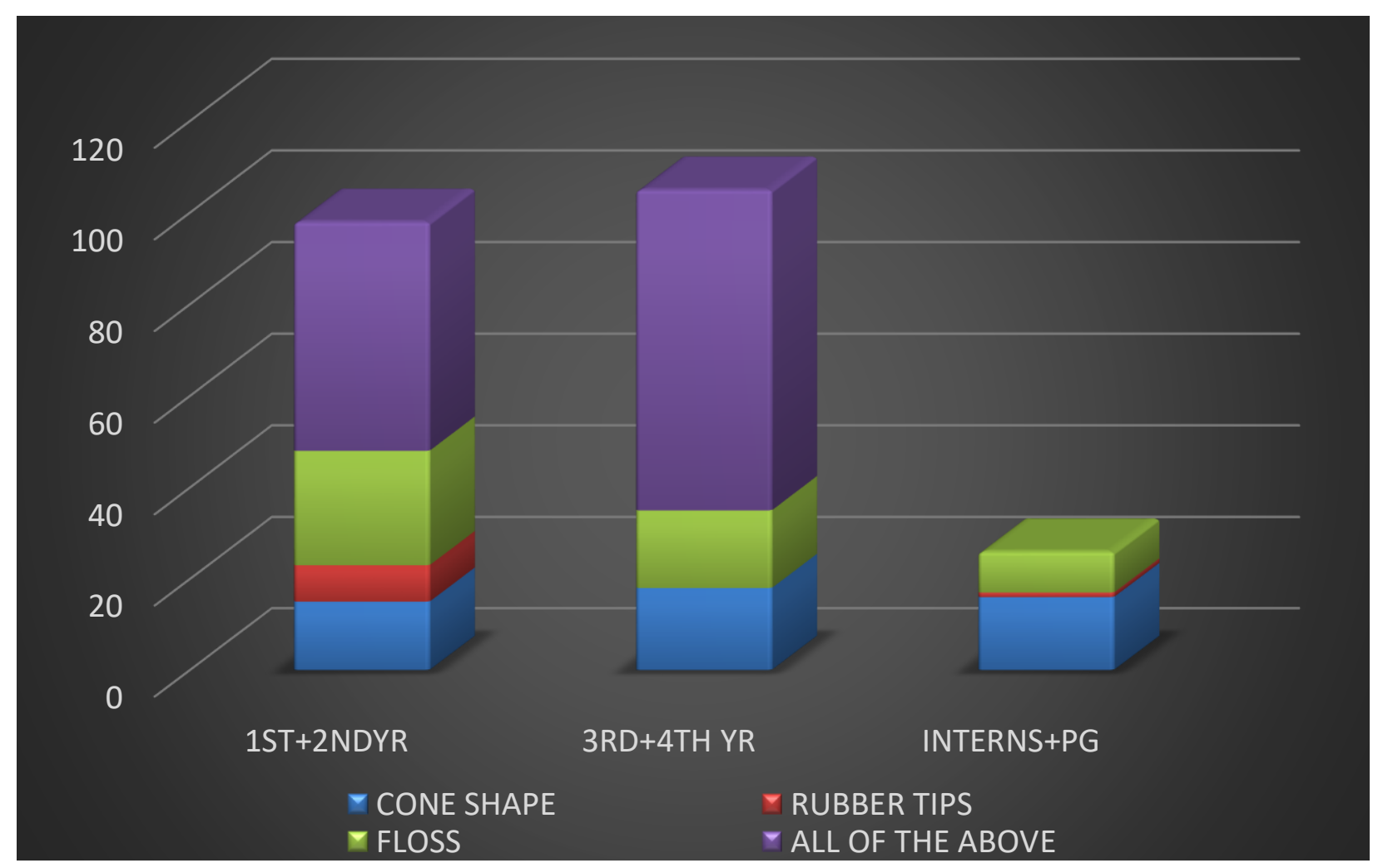




\section{PRACTICE}

\section{Do you clean your teeth with inter dental aids ?}

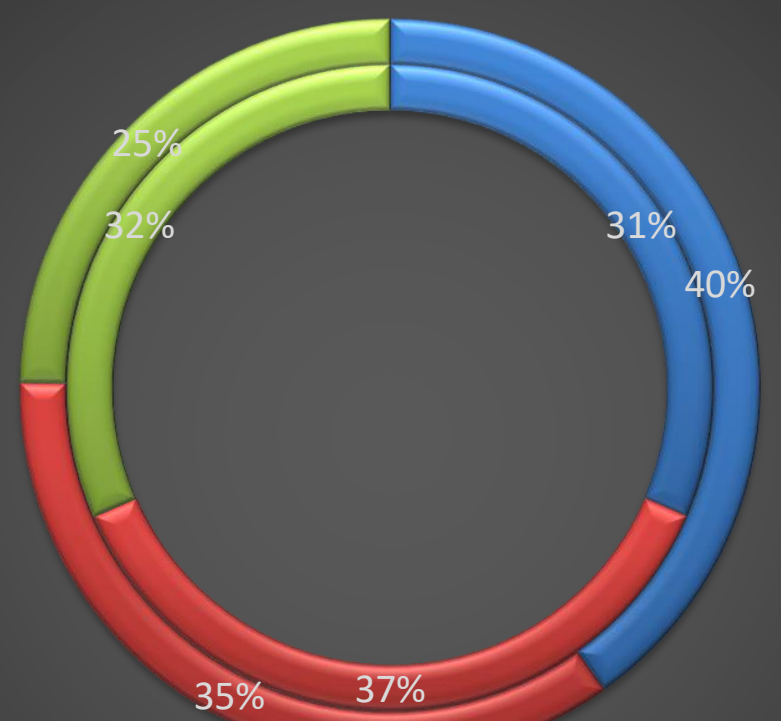

$\simeq 1 \mathrm{ST}+2 \mathrm{NDYR} \quad \square 3 \mathrm{RD}+4 \mathrm{TH} \mathrm{YR}$

\section{Which type of interdental cleansing aids you used ?}




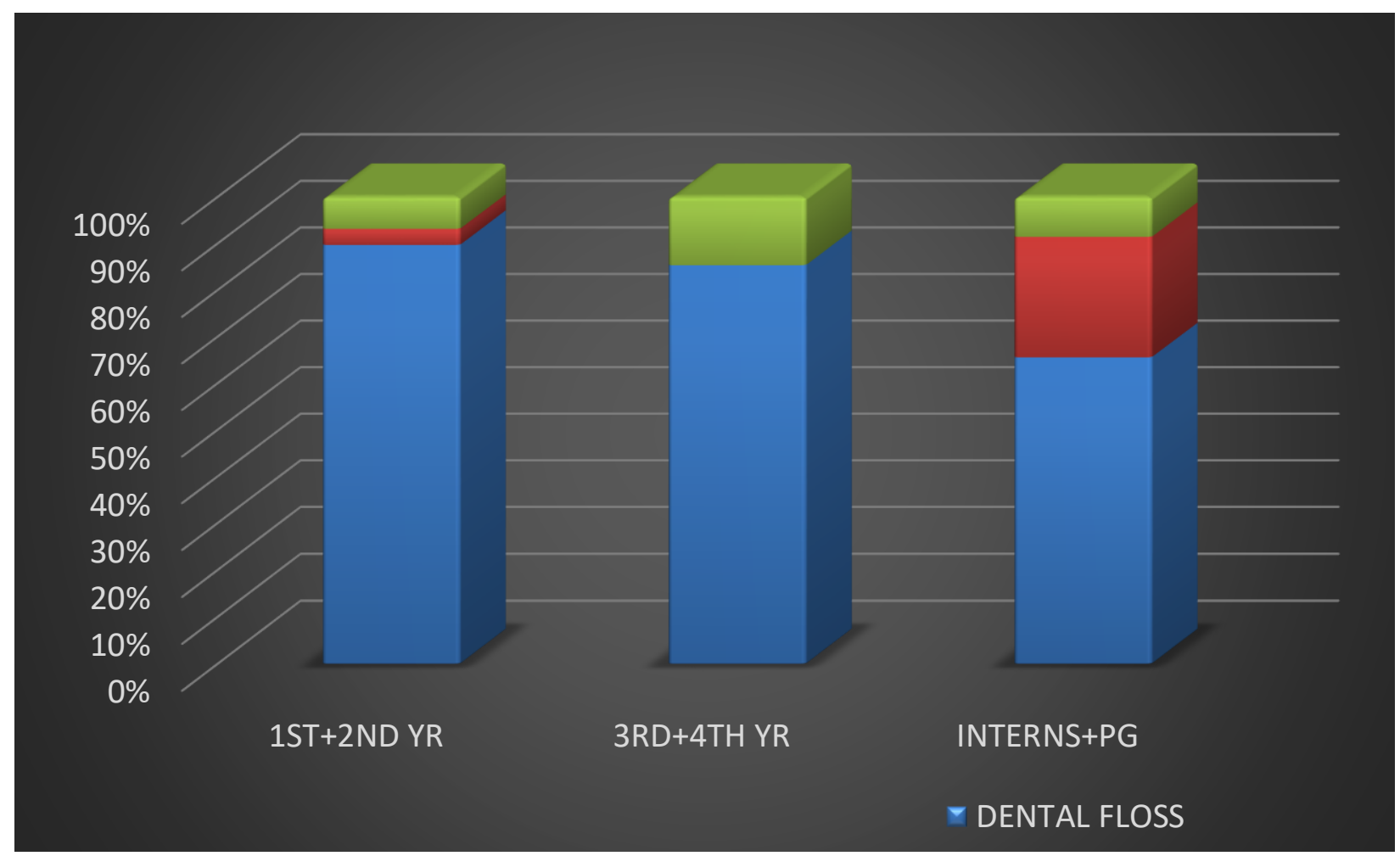

\section{Is it time consuming?}

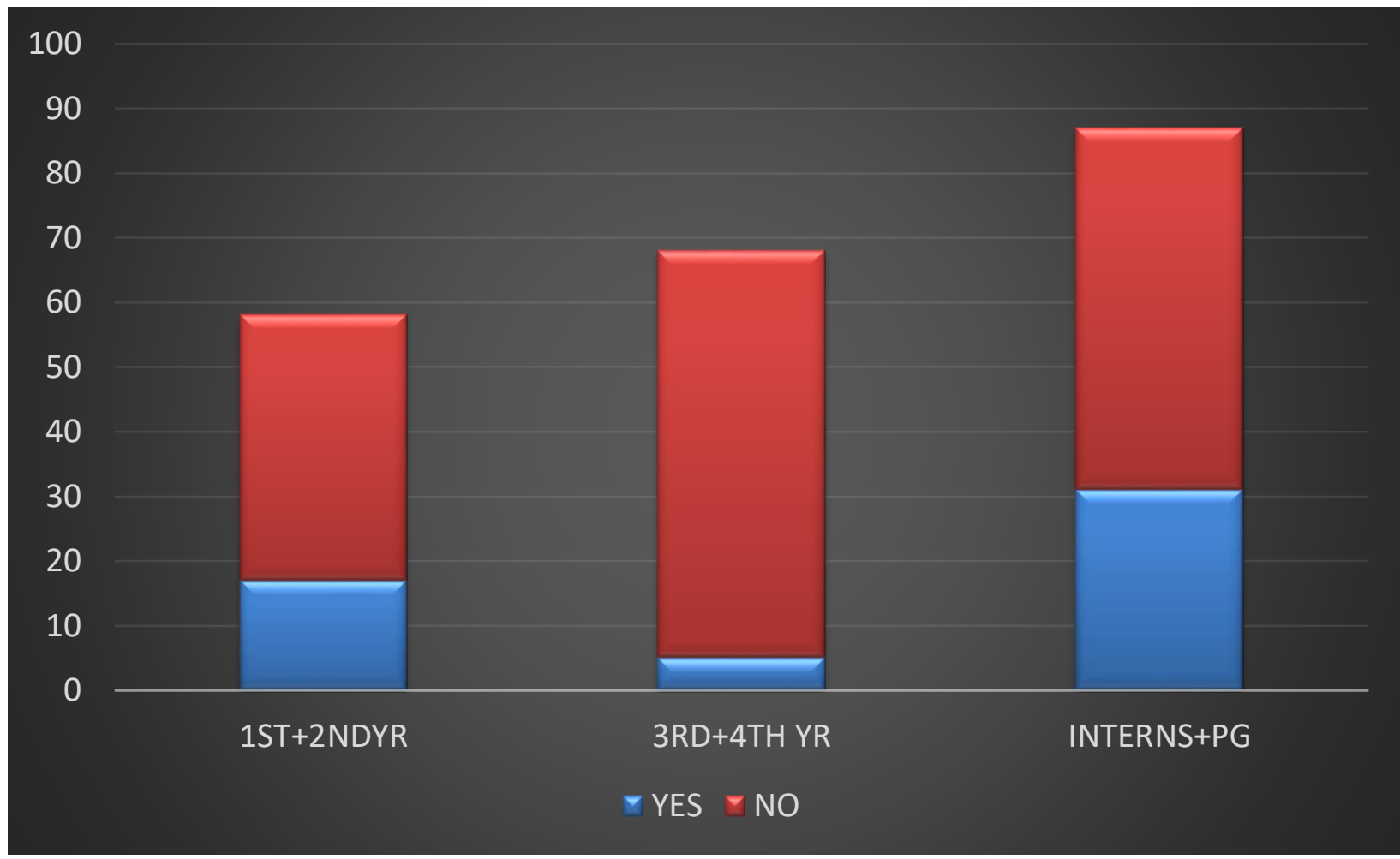


Is there any harmful effect on soft tissue?

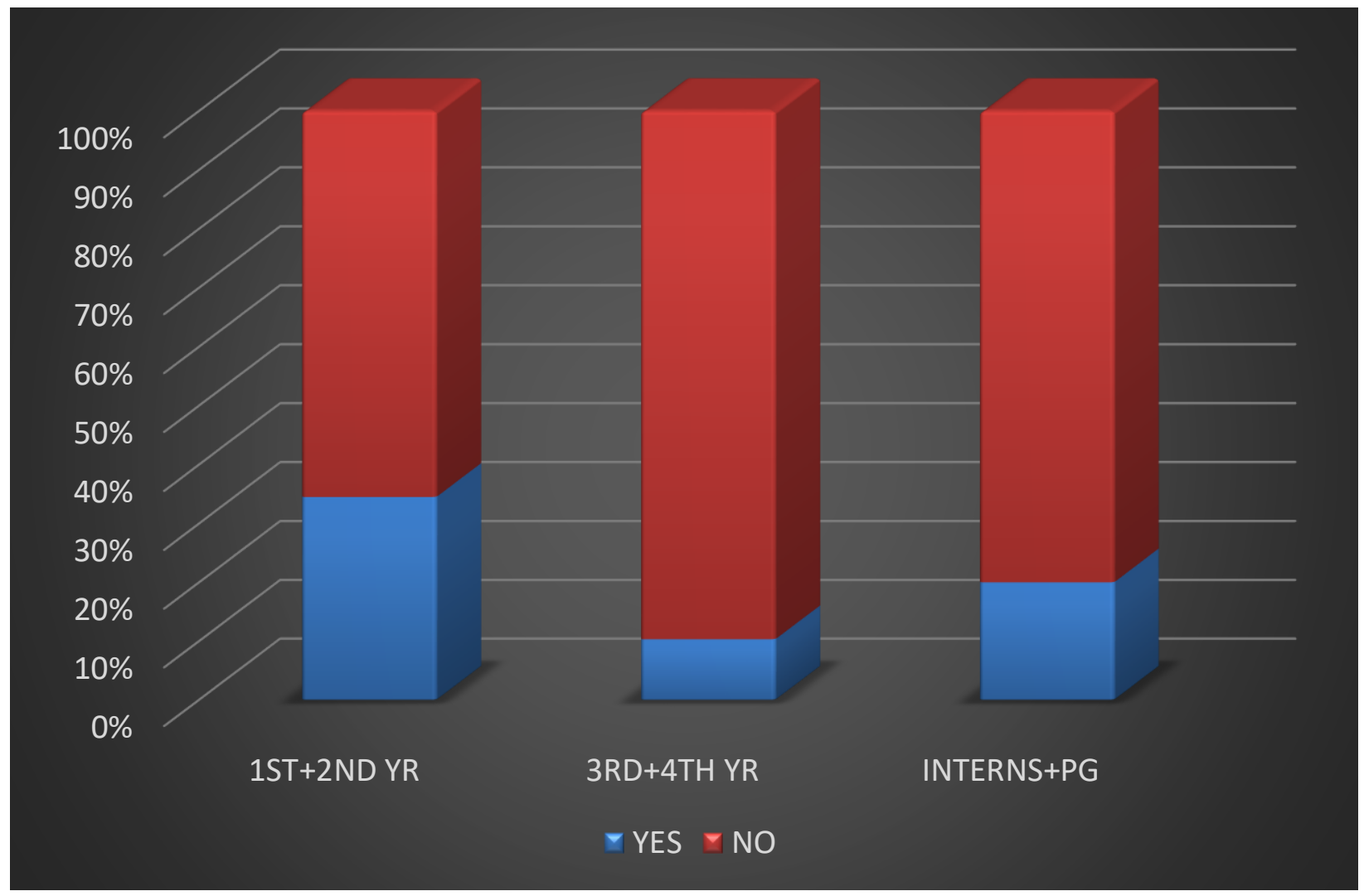

Are you happy with use of interdental cleansing aids?

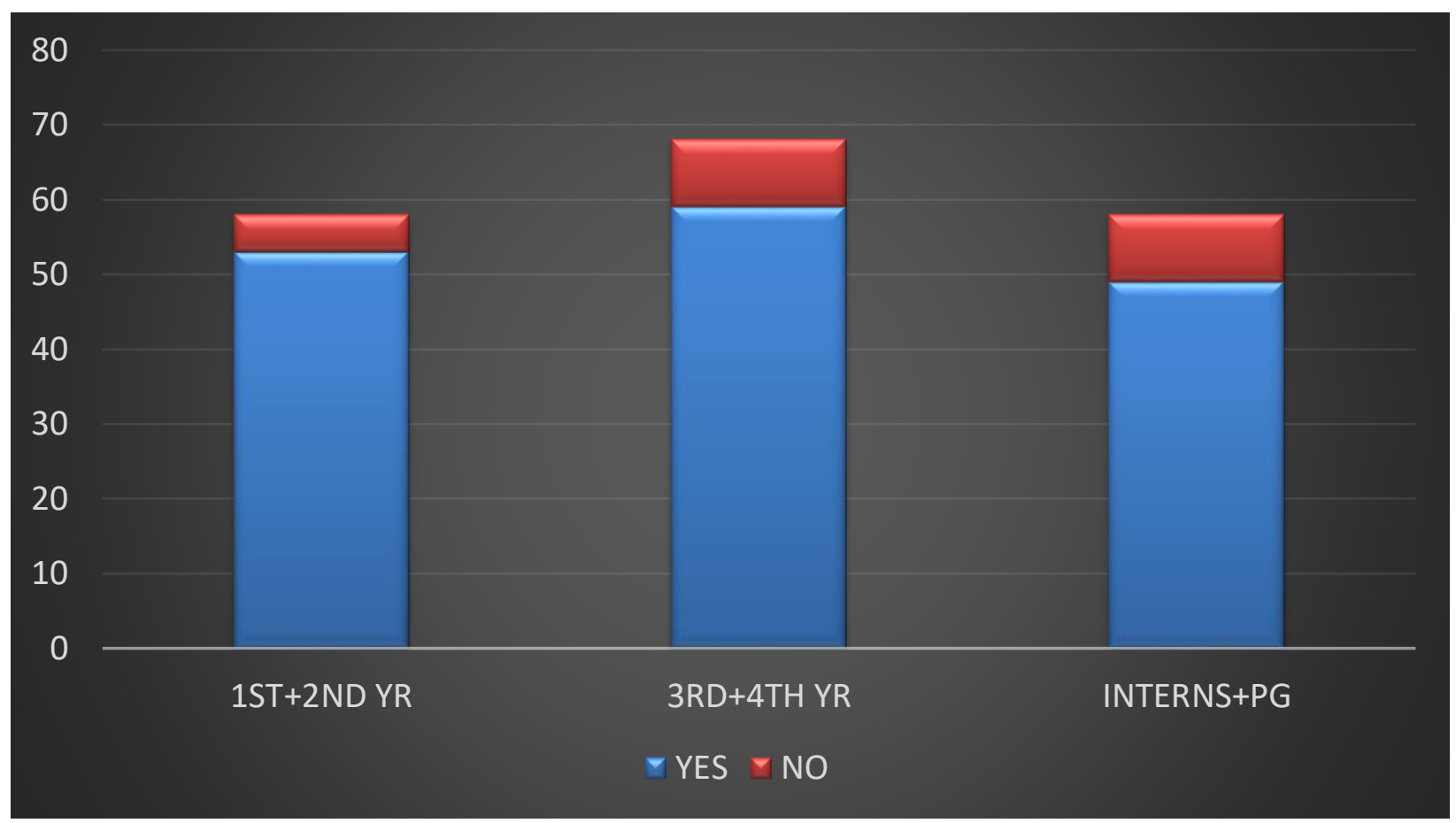


Did you recommend your patient to use interdental aids?

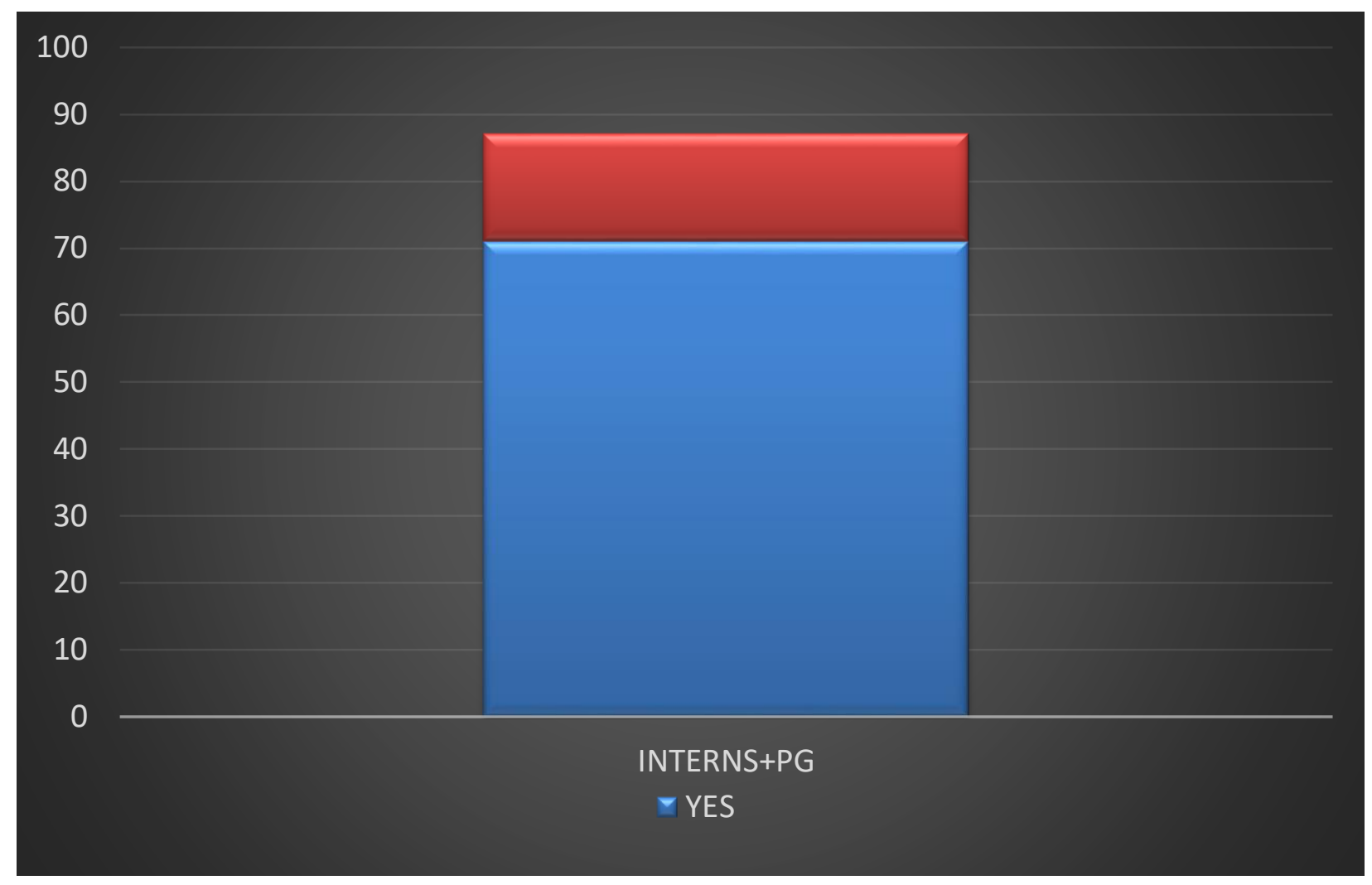

\section{DISCUSSION}

The present study has investigated the knowledge of oral hygiene aids and practice of it among dental student. Professional plaque removal and regular follow- up combined with patient oral hygiene instructions can minimize the level of gingival inflammation and swelling. ${ }^{10}$

The result of the study shows that dental students are quiet aware of the adjunctive use of interdental aids only few were relatively practicing it .Brushing was the most commonly used method of teeth cleaning. $90.3 \%$ of the total patients cleaned their teeth with toothbrush and toothpaste. In the present study about $20 \%$ of the total patients used any of the interdental aids, out of which only $9.8 \%$ subjects used dental floss, $6.9 \%$ patients used toothpick while only $3.2 \%$ subjects used any other interdental aid like interdental brush.

Knowledge and Awareness of interdental cleaning among the study participants

A total of $281(86.0 \%)$ patients were aware of interdental cleaning; $148(52.6 \%)$ got to know about interdental cleaning from the dentist and dental health workers, 33(11.7\%) from the mass media, $12(4.2 \%)$ from family, whereas $88(31.31 \%)$ were informed from other sources such as, physicians and medical health workers, spouse, and friends. The most commonly used interdental aid in this study was dental floss. This is similar to what had been reported by others. ${ }^{11,12} \mathrm{~A}$ review on interdental cleaning methods concluded that all conventional devices are effective, but each method should be suited to a particular patient and also to the situation in the mouth. ${ }^{13}$

Among 324 subject $184(56 \%)$ practising interdental aids. In the present study about $80 \%$ subjects used dental floss, $9.2 \%$ patients used toothpick while only $10.3 \%$ subjects used any other interdental aid like interproximal brush Although, PG students being $100 \%$ aware, the usage was limited. About $70 \%$ demonstrate their patients to use dental floss, $16 \%$ does not demonstrate the use of dental floss. Several studies have shown the usefulness of regular dental flossing for removal of inter dental plaque and calculus (Bauroth et al, 2003; Bellamy et al,2004). ${ }^{14,15}$ Just being aware is not only important the habit should be instilled since early stage for proper maintenance of oral hygiene. It was observed that a few of the study participants cleaned their teeth twice daily or more often, similar to findings from a previous study. ${ }^{16}$ This is suggestive of poor oral hygiene behaviour commoner among the patients, probably a contributing factor to the high prevalence of periodontal disease in this region of the world. 


\section{CONCLUSION}

Present Study showed the knowledge and practice of interdental aids among dental professionals. It should be noted more than $80 \%$ dental student are quite aware and knows about interdental cleansing aids, very few population relatively practicing it. Practicing interdental cleansing aids will help for maintaining of oral hygiene, for plaque control, and for prevention of periodontal disease. This study should be directed to evaluate the oral hygiene and gingival and periodontal status of those subjects using toothbrush alone and combination of toothbrush along with the interdental aids. This would educate the recommendation of interdental aids regularly.

\section{REFERENCES}

[1]. Socransky SS, Haffajee AD: Dental biofilms: difficult therapeutic targets. Periodontology 2002, 28:12-55.

[2]. Marsh PD: Dental plaque as a microbial biofilm. Caries Res 2004, 38:204-211.

[3]. Pinto TM, de Freitas GC, Dutra DA, Kantorski KZ, Moreira $\mathrm{CH}$. Frequency of mechanical removal of plaque as it relates to gingival inflammation: A randomized clinical trial. J Clin Periodontol 2013;40:948-54.

[4]. Claydon NC. Current concepts in tooth brushing and interdental cleaning. Periodontol 2000 2008;48:10-22.

[5]. Gluch JI. As an adjunct to tooth brushing, interdental brushes (IDBs) are more effective in removing plaque as compared with brushing alone or the combination use of tooth brushing and dental floss. J Evid Based Dent Pract 2012;12:81-3.

[6]. Kocher T, Sawaf H, Warncke M, Welk A. Resolution of interdental inflammation with 2 different modes of plaque control. J Clin Periodontol 2000;27:883-8.

[7]. Berchier CE, Slot DE, Haps S, Van der Weijden GA. The efficacy of dental floss in addition to a toothbrush on plaque and parameters of gingival inflammation: A systematic review. Int J Dent Hyg 2008;6:265-79.

[8]. Crocombe LA, Brennan DS, Slade GD, Loc DO. Is selfinterdental cleaning associated with dental plaque levels, dental calculus, gingivitis and periodontal disease? J Periodontal Res 2012;47:188-97.

[9]. Wolff A, Staehle HJ. Improving the mechanical properties of multiuse dental floss holders. Int J Dent Hyg 2014;12:245-50.

[10]. Tseveenjav, B., Vehkalahti, M.\& Murtomaa, H., (2004) Oral health and its determinants among Mongolian dentists. Acta Odontol Scand 62:1-6.steenbergen, T.J., Van der veld

[11]. Ziebolz D, Klopfleisch S, Fresmann S, Hornecker E, Mausberg RF. Oral health of dental assistants and patients receiving maintenance - An investigation based on a district of Thuringia, Germany. Int J Dent Hyg 2013;11:253-
ISSN No:-2456-2165

[12]. Bergenholtz A, Brithon J. Plaque removal by dental floss or toothpicks. An intra-individual comparative study. J Clin Periodontol 1980; 7:516-24

[13]. Warren PR, Chater BV. An overview of established interdental cleaning methods. J Clin Dent 1996;7:65-9.

[14]. Bauroth, K., Charles, C. H., Mankodi, S. M., Simmons, K., Zhao, Q. \& Kumar, L. D. (2003). The efficacy of an essential oil antiseptic mouthrinse vs. dental floss in controlling interproxi-mal gingivitis: a comparative study. Journal of the American Dental Association, 134, 359-365.

[15]. Bellamy, P., Barlow, A., Puri, G., Wright, K. I., Mussett, A. \& Zhou, X. (2004). A new in vivo interdental sampling method comparing a daily flossing regime versus a manual brush control. Journal of Clinical Dentistry, 15, 59-65

[16]. Lawal FB, Taiwo JO, Oke GA. Oral health practices of adult inhabitants of a traditional community in Ibadan, Nigeria. Niger J Med 2013;22:212-7. 